\title{
Analisis penggunaan alat magnetisasi bahan bakar secara elektromagnetik terhadap unjuk kerja mesin empat langkah satu silinder
}

\author{
M. Mara ${ }^{\star}$, W. Joniarta, IB. Alit, IM. A. Sayoga, M. Nuarsa \\ Teknik Mesin Fakultas Teknik Universitas Mataram, Jln. Majapahit No. 62 Mataram Nusa Tenggara \\ Barat Kode Pos: 83125, Telp. (0370) 636087; 636126; ext 128 Fax (0370) 636087. \\ *Email: made.mara@ymail.com
}

\section{ARTICLE INFO}

\section{Article History:}

Received 24 February 2018

Accepted 14 April 2018

Available online 1 July 2018

Keywords:

Electromagnetic field

Engine performance

Fuel consumption

Engine torque

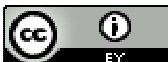

\begin{abstract}
The efforts to increase fuel economy and thrift the usage of fossil fuel are becoming main focus in the entire the world. One of those efforts is by using electromagnetic field in order to increase the quality of the combustion process and reducing fuel consumption. This research investigates the effect of the number of cooper wire winding on electromagnetic field on engine torque, engine power and fuel consumption of $100 \mathrm{cc}$ four stroke single cylinder gasoline engine. The numbers of cooper wire windings are, 3000, 4000 and 4500. The engine performance was analyzed at several engine rotations. The result shows that there is an increase of engine power by $12.83 \%$ and on the other hand the fuel consumption reduced by $10 \%$ on 4000 windings at $1500 \mathrm{rpm}$.
\end{abstract}

\section{PENDAHULUAN}

Pemakaian bahan bakar minyak sebagai salah satu sumber energi, mengalami peningkatan yang signifikan seiring pertumbuhan dan peningkatan kesejahteraan masyarakat. Hal ini berdampak pada makin meningkatnya kebutuhan akan sarana transportasi dan aktivitas industri. Minyak bumi merupakan sumber bahan bakar yang tidak dapat diperbaharui, maka meningkatnya penggunaan bahan bakar ini akan mengakibatkan cadangan minyak bumi terus berkurang. Keterbatasan sumber bahan bakar minyak bumi tersebut menjadi alasan utama mengapa kita bersama harus menghematnya.

Penghematan bahan bakar minyak menjadi sesuatu yang sangat penting. Selain penghematan, memperbaiki kualitas bahan bakar minyak juga perlu dilakukan sehingga akan menghasilkan emisi gas buang yang ramah lingkungan. Selain menggunakan bahan bakar alternatif yang ramah lingkungan, cara lain untuk mengurangi polusi adalah dengan meningkatkan efisiensi pembakaran pada mesin pembakaran dalam. Berbagai cara telah diupayakan dan diterapkan untuk meningkatkan efisiensi termal motor bakar, antara lain dengan meningkatkan efisiensi pembakaran, meningkatkan perbandingan kompresi, EFI (electronic fuel injection), VVT (variable valve timing), dan sebagainya. Sedangkan alat dan bahan aditif yang digunakan sebagai penghemat bahan bakar yaitu bahan aditif berupa tablet, cairan (misal XXL Fuel Booster) dan yang berupa peralatan misalnya difusor yang dipasang di dalam karburator, dan magnetic fuel saver (penghemat 
bahan bakar magnetis). (Abdulkadir dan Harianto, 2013).

Penghemat bahan bakar magnetis adalah sistem penghemat bahan bakar yang berupa magnet. Alat ini dipasang di saluran bahan bakar sebelum masuk ke karburator. Bahan bakar, dalam hal ini bensin, dialirkan lewat medan magnet akan menyebabkan perubahan orientasi kutub magnet dan konfigurasi molekul-molekul bahan bakar (Chaware, 2015). Magnet dimanfaatkan untuk menggetarkan (meresonansi) ion hidrokarbon dalam bahan bakar. Ionisasi diperlukan agar bahan bakar dapat dengan mudah mengikat oksigen selama proses pembakaran, sehingga campuran bahan bakar dan oksigen dapat terbakar dengan sempurna. Hal ini mengakibatkan peningkatan terhadap kinerja mesin. Dengan pemberian medan magnet yang berfungsi untuk mengionisasi bahan bakar pada saluran bahan bakar diharapkan akan meningkatkan kualitas bahan bakar. Dengan demikian akan meningkatkan prestasi mesin (Eryadi, dkk., 2012).

Untuk mengetahui besar pengaruh jumlah kumparan kawat pada alat magnetisasi bahan bakar dalam penelitian ini dilakukan analisis penggunaan alat magnetisasi bahan bakar secara elektromagnetik terhadap unjuk kerja mesin empat langkah satu silinder. Diameter kawat yang digunakan adalah 0,35 mm.

\section{METODE PENELITIAN}

Metode yang digunakan dalam penelitian ini adalah metode eksperimen. Jenis metode penelitian ini dapat dipakai untuk menguji suatu perlakuan atau desain baru dengan membandingkan satu atau lebih kelompok pengujian dengan perlakuan dan tanpa perlakuan.

Tahapan dalam pelaksanaan ini meliputi tahap persiapan, tahap pengujian dan tahap pengambilan data dan analisa

Dalam tahap persiapan dilakukan studi pustaka, observasi, dan pengadaan bahan dan peralatan. Selanjutnya dilakukan pengujian kinerja dari alat yang telah dibuat dengan variasi pengujian adalah jumlah lilitan elektromagnet 3500, 4000, dan 4500 lilitan kawat tembaga yang berdiameter $0,35 \mathrm{~mm}$. Variasi putaran mesin $1500 \mathrm{rpm}, 3000 \mathrm{rpm}, 4500 \mathrm{rpm}$, dan $6000 \mathrm{rpm}$. Sumber arus listrik untuk medan magnet diambil dari baterai dengan tegangan 12 volt. Dalam tahap pengambilan data dilakukan pengukuranpengukuran unjuk kerja mesin, meliputi putaran, torsi, daya, dan konsumsi bahan bakar. Dalam tahap analisis dilakukan perhitungan-perhitungan untuk menentukan korelasi matematis antara putaran dengan torsi, daya dan konsumsi bahan bakar, baik pada kondisi tanpa dan terpasang alat magnetisasi bahan bakar.

Rancangan alat penghemat bahan bakar dibuat seperti gambar berikut ini.

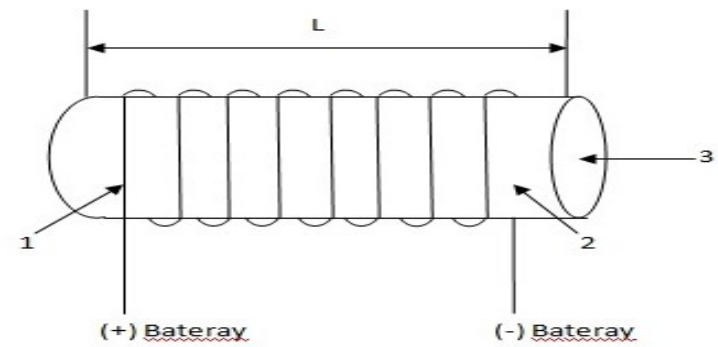

1. Kawat kumparan, 2. Pipa induktor, 3. Saluran bahan bakar

Gambar 1. Rancangan kawat kumparan

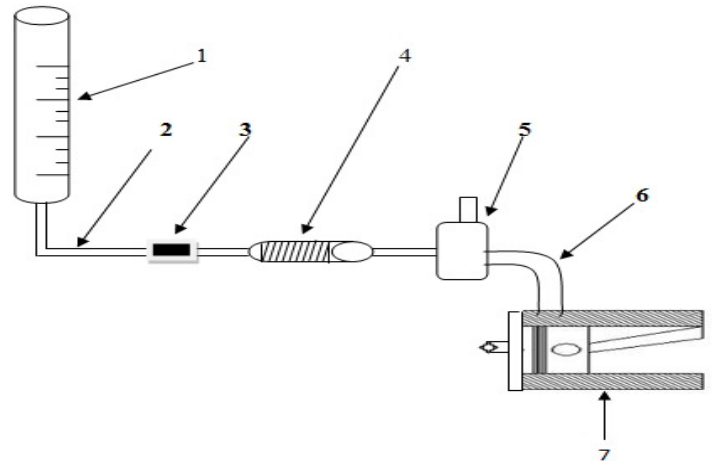

1. Gelas ukur, 2. Selang minyak, 3. Filter Bensin, 4. Alat Magnetisasi Bahan Bakar, 5. Karburator, 6. Intake manifold, 7. Ruang Bakar Bahan Bakar

Gambar 2. Rancangan alat pengujian

\section{HASIL DAN PEMBAHASAN}

Nilai torsi yang dikeluarkan oleh kendaraan uji dapat diketahui dengan cara mengalikan antara gaya pengereman dengan jari jari alat ukur torsi (Arismunandar, 1988).

$T=F r$

Dengan $T$ adalah torsi (kgfm), $F$ merupakan gaya tangensial stator (kgf), dan $r$ adalah radius gaya yang bekerja $(\mathrm{m})$.

Tabel 1. Data torsi hasil perhitungan (Kgfm)

\begin{tabular}{ccccc}
\hline \multirow{2}{*}{ Putaran (Rpm) } & \multicolumn{4}{c}{ Jumlah Lilitan (N) } \\
\cline { 2 - 5 } & Standar & 3500 & 4000 & 4500 \\
\hline \multirow{2}{*}{1500} & 0.04 & 0.04 & 0.04 & 0.04 \\
& 0.04 & 0.04 & 0.04 & 0.04 \\
Rata-rata & 0.04 & 0.04 & 0.04 & 0.04 \\
\hline
\end{tabular}




\begin{tabular}{ccccc}
\hline \multirow{3}{*}{3000} & 0.33 & 0.42 & 0.42 & 0.42 \\
& 0.37 & 0.37 & 0.37 & 0.37 \\
& 0.33 & 0.37 & 0.42 & 0.37 \\
Rata-rata & 0.35 & 0.39 & 0.40 & 0.39 \\
4500 & 0.62 & 0.71 & 0.71 & 0.66 \\
& 0.66 & 0.66 & 0.66 & 0.66 \\
Rata-rata & 0.66 & 0.66 & 0.71 & 0.66 \\
& 0.65 & 0.68 & 0.69 & 0.66 \\
6000 & 0.75 & 0.83 & 0.83 & 0.79 \\
& 0.71 & 0.75 & 0.83 & 0.75 \\
Rata-rata & 0.71 & 0.75 & 0.79 & 0.75 \\
& 0.72 & 0.77 & 0.82 & 0.76 \\
\hline
\end{tabular}

Dari data hasil perhitungan torsi yang diperoleh dapat dibuat grafik hubungan torsi terhadap putaran mesin.

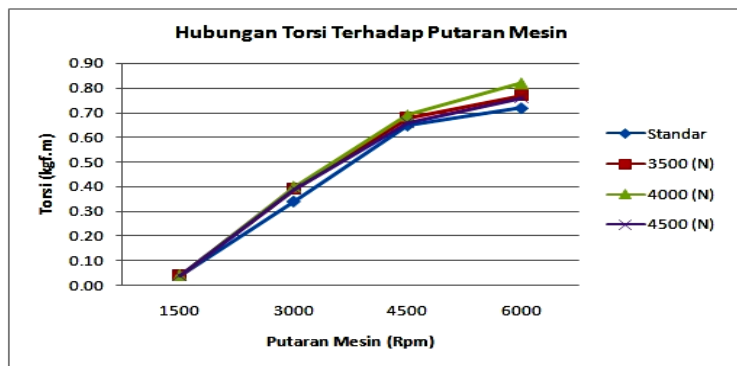

Gambar 3. Hubungan torsi terhadap putaran

Berdasarkan gambar 3 pengaruh torsi terhadap putaran mesin, dapat diketahui bahwa torsi yang dihasilkan meningkat berbanding lurus dengan meingkatnya putaran mesin.

Dari ke empat percobaan yang dilakukan, didapatkan torsi tertinggi pada variasi jumlah lilitan 4000 lilitan dengan torsi sebesar 0,82 kgf.m. Torsi terendah dihasilkan pada mesin tanpa menggunakan alat magnetisasi bahan bakar dengan torsi sebesar 0,72 kgf.m pada putaran $6000 \mathrm{rpm}$ dengan peningkatan torsi sebesar $12,50 \%$.

Hal ini terjadi karena pemberian medan magnet pada bahan bakar akan mempengaruhi struktur molekul hidrokarbon yang terkandung dalam bahan bakar yang menyebabkan terjadinya pemecahan hidrokarbon menjadi bagian yang lebih kecil dan berjajar rapi antara atom hidrogen $(\mathrm{H})$ dan atom karbon $(\mathrm{C})$ sehingga akan lebih mudah bereaksi dengan oksigen yang didapatkan dari udara luar dan menghasilkan pembakaran yang lebih sempurna. Pembakaran yang sempurna akan menghasilkan torsi meningkat dan mengurangi emisi gas buang hidrokarbon (HC)(Ismawan, dkk., 2010).

Besarnya daya efektif $(\mathrm{Ne})$ tergantung dari besarnya torsi dan putaran yang terjadi. Hal ini dapat dilihat dari persamaan (Arismunandar, 1988)

$$
N e=\frac{T . n}{716,2}
$$

dengan $\mathrm{Ne}$ adalah daya efektif (PS), dan $\mathrm{n}$ menyatakan putaran mesin (rpm).

Tabel 2. Daya efektif hasil perhitungan (PS).

\begin{tabular}{ccccc}
\hline \multirow{2}{*}{ Putaran (Rpm) } & \multicolumn{4}{c}{ Jumlah Lilitan (N) } \\
\cline { 2 - 5 } 1500 & Standar & 3500 & 4000 & 4500 \\
\hline \multirow{2}{*}{ Rata-rata } & 0.08 & 0.08 & 0.08 & 0.08 \\
& 0.08 & 0.08 & 0.08 & 0.08 \\
3000 & 0.08 & 0.08 & 0.08 & 0.08 \\
& 1.37 & 1.74 & 1.74 & 0.08 \\
Rata-rata & 1.53 & 1.53 & 1.53 & 1.53 \\
& 1.37 & 1.53 & 1.74 & 1.53 \\
4500 & 1.42 & 1.60 & 1.67 & 1.60 \\
& 3.86 & 4.42 & 4.42 & 4.11 \\
Rata-rata & 4.11 & 4.11 & 4.11 & 4.11 \\
& 4.11 & 4.11 & 4.42 & 4.11 \\
6000 & 4.02 & 4.21 & 4.31 & 4.11 \\
& 6.22 & 6.88 & 6.88 & 6.55 \\
Rata-rata & 5.89 & 6.22 & 6.88 & 6.22 \\
& 5.89 & 6.22 & 6.55 & 6.22 \\
& 6.00 & 6.44 & 6.77 & 6.33 \\
\hline
\end{tabular}

Dari tabel data hasil perhitungan daya efektif $(\mathrm{Ne})$ yang diperoleh dapat dibuat grafik hubungan daya efektif terhadap putaran.

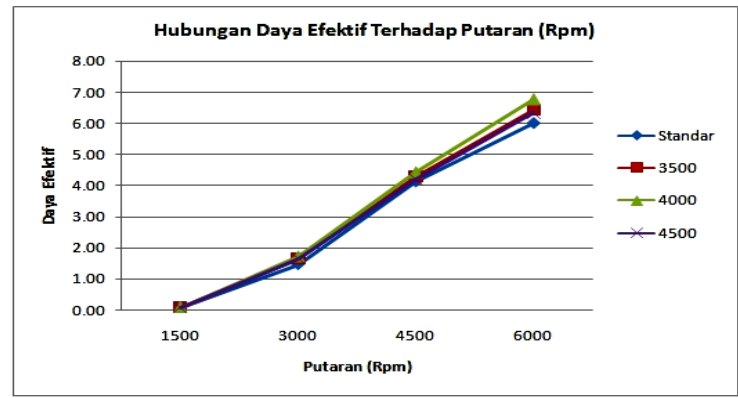

Gambar 4. Hubungan daya efektif terhadap putaran

Berdasarkan gambar 4 di atas terlihat bahwa daya efektif yang dihasilkan meningkat seiring dengan meningkatnya putaran mesin. Hal ini dikarenakan dengan bertambahnya putaran mesin berbanding lurus dengan jumlah pembakaran per menit. Daya efektif tertinggi dihasilkan pada variasi 4000 lilitan sebesar 6,77 PS, sedangkan daya efektif terendah dihasilkan pada percobaan tanpa alat magnetisasi bahan bakar sebesar 6,00 PS pada putaran $6000 \mathrm{rpm}$, dengan selisih penurunan daya efektif yang terjadi sebesar $12,83 \%$. Hal ini disebabkan karena pada variasi jumlah lilitan 4000 lilitan besar medan magnet yang dihasilkan paling 
besar yaitu sebesar 914,2 gauss jika dibandingkan dengan variasi 3500 lilitan atau 4500 lilitan, sehingga bahan bakar yang terkena magnetisasi lebih banyak dan pembakaran akan lebih sempurna sehingga daya mesin yang dihasilkan juga lebih besar.

Fuel consumption merupakan ukuran pemakaian bahan bakar yang digunakan untuk menjalankan suatu mesin selama priode waktu tertentu, dan biasanya diukur dalam satuan berat bahan bakar per satuan waktu. Besarnya fuel consumption (FC) bensin dapat dihitung dengan persamaan.

$$
F c=\frac{V f}{t} \rho \frac{3.600}{100.000 .000}
$$

dengan FC adalah fuel consumption (kg / jam), Vf menyatakan volume pemakaian bahan bakar (ml), t adalah waktu (detik), dan $\rho$ adalah massa jenis $\left(\mathrm{kg} / \mathrm{m}^{3}\right)$.

Tabel 3. Hasil perhitungan fuel consumption (kg/Jam)

\begin{tabular}{ccccc}
\hline \multirow{2}{*}{ Putaran (Rpm) } & \multicolumn{4}{c}{ Jumlah Lilitan (N) } \\
\cline { 2 - 5 } 1500 & Standar & 3500 & 4000 & 4500 \\
\hline \multirow{3}{*}{ Rata-rata } & 0.11 & 0.11 & 0.11 & 0.11 \\
& 0.11 & 0.11 & 0.09 & 0.11 \\
\multirow{2}{*}{3000} & 0.11 & 0.11 & 0.11 & 0.11 \\
& 0.24 & 0.22 & 0.10 & 0.11 \\
Rata-rata & 0.24 & 0.22 & 0.21 & 0.23 \\
& 0.24 & 0.21 & 0.22 & 0.22 \\
4500 & 0.24 & 0.22 & 0.21 & 0.23 \\
& 0.38 & 0.37 & 0.36 & 0.37 \\
Rata-rata & 0.37 & 0.36 & 0.35 & 0.38 \\
& 0.38 & 0.37 & 0.35 & 0.37 \\
6000 & 0.38 & 0.37 & 0.35 & 0.37 \\
& 0.49 & 0.48 & 0.46 & 0.48 \\
Rata-rata & 0.49 & 0.46 & 0.45 & 0.46 \\
& 0.47 & 0.47 & 0.47 & 0.48 \\
& 0.48 & 0.47 & 0.46 & 0.48 \\
\hline
\end{tabular}

Konsumsi bahan bakar efektif atau specific fuel consumption effective (SFCe) ditentukan dengan persamaan (Arismunandar, 1988).

$S F C e=\frac{F c}{N e}$

dimana $\mathrm{Ne}$ adalah daya efektif (PS).

SFCe sebagai parameter yang biasa dipakai sebagai ukuran ekonomi pemakaian bahan bakar yang dipakai per jam untuk setiap daya yang dihasilkan. Harga SFCe yang lebih rendah menyatakan efisiensi yang lebih tinggi.

Tabel 4. Specific fuel consumption effective (SFCe) hasil pengukuran (kg/PS.jam)

\begin{tabular}{ccccc}
\hline \multirow{2}{*}{ Putaran (Rpm) } & \multicolumn{5}{c}{ Jumlah Lilitan (N) } \\
\cline { 2 - 5 } 1500 & Standar & 3500 & 4000 & 4500 \\
\hline \multirow{3}{*}{ Rata-rata } & 1.36 & 1.31 & 1.29 & 1.32 \\
& 1.34 & 1.14 & 1.12 & 1.20 \\
3000 & 1.34 & 1.18 & 1.16 & 1.23 \\
& 0.17 & 1.21 & 1.19 & 1.25 \\
Rata-rata & 0.16 & 0.14 & 0.12 & 0.13 \\
& 0.17 & 0.14 & 0.14 & 0.15 \\
4500 & 0.17 & 0.14 & 0.13 & 0.14 \\
& 0.10 & 0.08 & 0.08 & 0.09 \\
Rata-rata & 0.09 & 0.09 & 0.09 & 0.09 \\
& 0.09 & 0.09 & 0.08 & 0.09 \\
6000 & 0.09 & 0.09 & 0.08 & 0.09 \\
& 0.08 & 0.07 & 0.07 & 0.07 \\
Rata-rata & 0.08 & 0.07 & 0.07 & 0.07 \\
& 0.08 & 0.08 & 0.07 & 0.08 \\
& 0.08 & 0.07 & 0.07 & 0.07 \\
\hline
\end{tabular}

Dari data hasil perhitungan fuel consumption (FC) dan Specific Fuel Consumption effective (SFCe), dapat dibuat grafik hubungan konsumsi bahan bakar spesifik terhadap putaran.

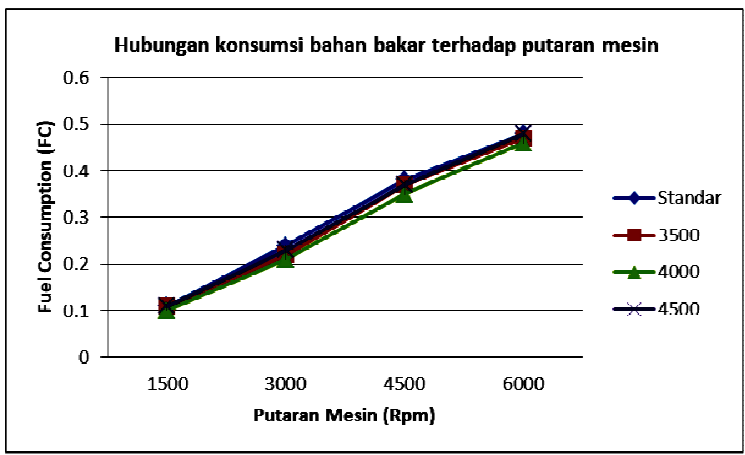

Gambar 5. Hubungan kosumsi bahan bakar terhadap putaran

Pada putaran mesin 1500 rpm sampai $6000 \mathrm{rpm}$ mengalami perubahan nilai konsumsi bahan bakar untuk masing masing variasi jumlah lilitan alat magnetisasi bahan bakar, di mana pada percobaan tanpa menggunakan alat magnetisasi dengan putaran mesin 1500 rpm mengkonsumsi bahan bakar rata-rata sebesar $0,10 \mathrm{~kg} / \mathrm{jam}$, hal ini dikarenakan pada putaran 1500 rpm laju aliran bahan bakar tidak terlalu cepat ataupun tidak terlalu lambat sehingga struktur molekul hidrokarbon yang terkena magnetisasi akan langsung bereaksi dengan oksigen, dan pada variasi 4000 lilitan besar 
medan magnet yang dihasilkan sebesar 914,2 Gauss. Terjadinya magnetisasi pada bahan bakar akan mengakibatkatan bahan bakar lebih mudah mengikat oksigen selama proses pencamuran sehingga proses pembakaran akan lebih baik dan mengurangi produk hidrokarbon (HC) yang tidak terbakar dalam proses pembakaran. Proses magnetisasi pada bahan bakar akan membuat pembakaran lebih sempurna dengan terjadinya pembakaran yang sempurna maka konsumsi bahan bakar yang dibutuhkan lebih sedikit.

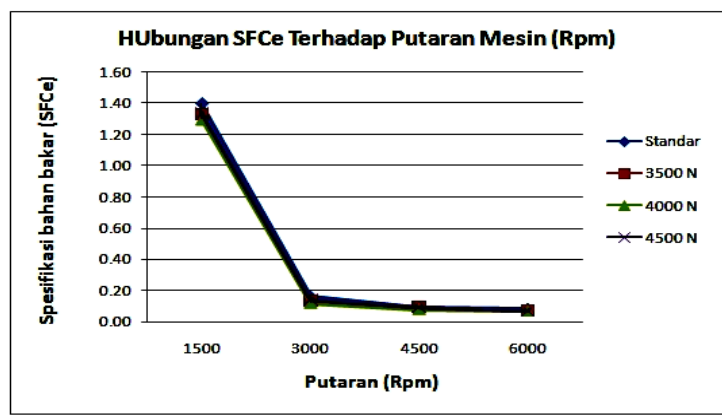

Gambar 6. Hubungan SFCe terhadap putaran mesin.

Pada gambar 6 di atas nilai SFCe tertinggi dihasilkan pada percobaan tanpa alat magnetisasi sebesar 1,35 kg/jam.PS padaputaran $1500 \mathrm{rpm}$. SFCe terendah dihasilkan pada variasi 4000 lilitan sebesar 0,07 $\mathrm{Kg} / \mathrm{jam} . \mathrm{PS}$ pada putaran $6000 \mathrm{rpm}$.

Dengan adanya perubahan jumlah lilitan pada alat magnetisasi bahan bakar berbasis elektromagnetik dari 3500 lilitan menjadi 4000 lilitan dan 4500 lilitan dengan menggunakan baterai 12 volt menghasilkan medan magnet sebesar 821,4 Gauss pada variasi 3500 lilitan, dan besar medan magnet yang di hasilkan pada variasi 4000 lilitan sebesar 914,2 Gauss, dan 810,3 Gauss pada variasi 4500 lilitan.

Semakin besar medan magnet yang digunakan untuk memagnetisasi bahan bakar, semakin besar juga penurunan konsumsi bahan bakar spesifik (SFCe). Hal ini dikarenakan penggunaan medan magnet pada saluran bahan bakar dapat meningkatkan kesempurnaan campuran bahan bakar. Campuran bahan bakar yang terbakar dalam ruang bakar semakin sempurna ketika ikatan hidrokarbon lebih mudah untuk mengikat oksigen $\left(\mathrm{O}_{2}\right)$ selama proses pembakaran terjadi.

\section{KESIMPULAN}

Berdasarakan hasil penelitian, kemudian melakukan analisa data dan pembahasan dapat ditarik kesimpulan sebagai berikut:
1. Jumlah lilitan kumparan alat penghemat bahan bakar berbasis elektromagnetik berpengaruh terhadap torsi, daya, FC dan SFCe yang dihasilkan jika dibandingkan dengan percobaan tanpa menggunakan alat magnetisasi bahan bakar.

2. Konsumsi bahan bakar terendah terjadi pada variasi jumlah lilitan 4000 lilitan sebesar 0,10 $\mathrm{kg} / \mathrm{jam}$, pada putaran $1500 \mathrm{rpm}$, dengan penurunan $10 \%$. Konsumsi bahan bakar tertinggi didapatkan pada percobaan tanpa menggunakan alat magnetisasi bahan bakar dengan konsumsi bahan bakar sebesar 0,48 $\mathrm{kg} / \mathrm{jam}$ pada putaran $6000 \mathrm{rpm}$.

3. SFCe terendah didapatkan pada variasi jumlah lilitan 4000 lilitan sebesar 0.07 $\mathrm{kg} / \mathrm{jam} . \mathrm{PS}$, dan SFCe tertinggi didapatkan pada percobaan tanpa alat magnetisasi bahan bakar sebesar 1,35 kg/jam.PS pada putaran $1500 \mathrm{rpm}$.

\section{DAFTAR NOTASI}

$$
\begin{array}{ll}
\mathrm{F} & : \text { gaya tangensial stator, }(\mathrm{kgf}) \\
\mathrm{FC} & : \text { fuel consumtion }(\mathrm{kg} / \mathrm{jam}) \\
\mathrm{n} & : \text { putaran mesin }(\mathrm{rpm}) \\
\mathrm{Ne} & : \text { daya efektif }(\mathrm{PS}) \\
\mathrm{r} & \text { : radius gaya yang bekerja }(\mathrm{m}) \\
\mathrm{T} & : \text { torsi }(\mathrm{kgf} . \mathrm{m}) \\
\mathrm{t} & : \text { waktu (detik) } \\
\mathrm{Vf} & : \text { volume pemakaian bahan bakar }(\mathrm{ml}) \\
\rho & : \text { massa jenis }\left(\mathrm{kg} / \mathrm{m}^{3}\right)
\end{array}
$$

\section{DAFTAR PUSTAKA}

Abdulkadir M., Harianto, 2013, Pengaruh pemasangan alat penghemat bahan bakar magnetis terhadap efisiensi dan konsumsi bahan bakar spesifik motor bensin, Jurnal Rekayasa Teknologi Industri dan Informasi, STTNAS Yogyakarta.

Arismunandar W., 1988, Motor bakar torak,; ITB Bandung.

Chaware K., 2015, Review on effect of fuel magnetism by varying intensity on performance and emission of single cylinder four stroke diesel engine, International Journal of Engineering Research and General Science, Volume 3, Issue 1, ISSN 2091-2730.

Eryadi D., Putra T.D., Endayani I.D., 2012, Pengaruh penggunaan alat penghemat bahan bakar berbasis elektromagnetik terhadap unjuk kerja mesin diesel, Jurusan Teknik Mesin, Universitas Widyagama Malang, Vol.4, No. 2, 5-9.

Ismawan A.L., Wiyono S., Aklis N., 2010, Pengaruh pemasangan alat peningkat kualitas bahan bakar terhadap unjuk kerja dan konsumsi bahan bakar spesifik motor 
bensin, Jurnal Teknik Mesin, Universitas Muhammadiyah Surakarta, Vol.11, No. 1,

30-36. 